\section{Autonomic nervous system}

Structure of the Autonomic Nervous System. By G. Gabella. Pp. viii +214 . (Chapman and Hall: London; Halsted: New York, June 1976.) £9.80.

DR Gabei.la has produced an informative account of the structure of the autonomic nervous system. It is given in small compass (160 pages), and the author has also restricted his historical introduction to just over a page. The book then examines the structural anatomy of sympathetic ganglia and peripheral sympathetic nerves, including their development and regeneration. Parasympathetic structures, including the ciliary ganglia and the vagus nerve, are then described. The last chapter is devoted to the innervation of organs, including the eye, salivary glands, skin, adipose tissue, gut, the heart, blood vessels, respiratory tract and the genital tracts. The monograph is well supported by 800 references which are helpfully arranged at the end of the book in alphabetical order. The references quoted are recent, and many have been published in the $1970 \mathrm{~s}$ up to 1975 . The information is based on comparative anatomy and there is. frequent mention of the species on which the observations have been made.

Thus the book provides well documented information on the structures described, and will be valuable as a source of reference to anyone who is dealing with the structural anatomy of the autonomic nervous system in animals as well as man. The book has, however, some limitations. On the production side it seems unfortunate that the error in binding-the plates have been incorrectly placed-should not have been corrected, so that the publishers have only noted the error with an erratum slip. It is nevertheless a well produced and attractive volume. There are also some deficiencies in its composition: structure has been interpreted as histology rather than gross anatomy, and the book provides only limited information about the anatomical distribution of nerves. Thus description of the variations in the sympathetic outflow and its links with the sympathetic chain ('prefixing' and 'postfixing') are not included. The autonomic innervation of the eye is restricted to a discussion of two tissues only-the iris and the nictitating membrane-and there is no discussion of the eyelid. On the structural side the information is chiefly relevant to the peripheral autonomic nervous system, and details of the central nervous system are limited. So limited are they, that 'spinal cord' and 'hypothalamus' do not occur in the index and the chapter on the central nervous system (chapter 9) is only 3.5 pages long.

The description of the book explains that it is intended as a basic reference work on the autonomic nervous system for students of, and research workers in, the fields of physiology, pharmacology and neurobiology. As a description of the anatomical structures of the autonomic nervous system at a histological level, it is excellent. But it provides only limited information on the physiological mechanisms involved, and the pharmacology of the system is only briefly discussed, there being no biochemical information throughout the book. Clinical research workers will

\section{Noctilucent clouds}

Noctilucent Clouds. By V. A. Bronshten and N. I. Grishin. Pp. v+237. (Israel Program for Scientific Translations: Jerusalem; Wiley: Chichester, February 1976.) £8.25; $\$ 16.50$.

Ever since the first observations in 1885, noctilucent clouds have been a challenge to atmospheric physicists, in particular to those dealing with problems related to the upper atmosphere. Apart from data on meteors, information on the $80-\mathrm{km}$ region, where the clouds are situated, was almost nonexistent until rocket measurements became available some twenty years ago. Thus, for about seventy years, noctilucent clouds provided a playground for scientists with skill and imagination.

Noctilucent clouds also differ from most other problems in science in the following respect: during ninety years of research an enormous amount of data on various aspects of the problem has been collected and yet the two main problems remain unsolved: how do noctilucent clouds form and what do they consist of?

Since the early 1950 s, V. A. Bronshten and N. I. Grishin have contributed much to our knowledge of noctilucent clouds, and their names are well known to colleagues all over the world. In view of their contact with the problem over such a long timespan, they are in the best possible position to undertake such a comprehensive presentation of the history and state of the art of noctilucent clouds.

The book is obviously meant to cover the subject of noctilucent clouds exhaustively, and in large measure the authors have succeeded in their ambitious goal. The huge amount of information on the history of theories, abandoned or still under consideration, and on observational data and tech- also find that it does not provide any information on pathology or the clinical relevance of any of the structures described. It may, however, be argued that this was not the intention of the book

This book can be strongly recommended as a work of reference for any worker engaged in the study of the autonomic nervous system. It should also be available in libraries, but I feel that its information is too restricted for students or most clinical research workers. $\quad$ R. H. Johnson

Dr Jolinson is Senior Lecturer in the Department of Neurology, University of Glasgow, and Consultant Neurologist at the Institute of Neurological Sciences, Glasgow. UK.

niques, classifies the book as far the most useful and comprehensive source for students at all levels. One may say that there is a bias towards citing the results of Russian scientists. For readers from Western countries, however, this is an advantage rather than a weakness, since it makes available material which is otherwise difficult to obtain.

In the reviewer's opinion the greatest value of the book is to be found in the first four of the book's six chapters: history; range of distribution and frequency of occurrence; morphology and dynamics; and luminosity. All these chapters are very comprehensive and very well presented-not surprising, since this is where the authors have their primary interest and competence. Chapter 5 on the nature of noctilucent clouds is not as complete and up to date as one might wish. The manuscript of the book was, however, finished in June 1969, and much of the information about mesospheric humidity has become available since then. The historical paper by Bates and Nicolet on water vapour in the high atmosphere clearly deserves due reference, and photochemical models with eddy transport, pointing at a humid mesopause, were also available.

This book will be a valuable reference for all those interested in noctilucent clouds.

Eigil Hesstvedt

Eigil Hesstvedt is Professor in the Institute of Geophysics. University of Oslo, Norway.

- In the review of The Hydrolysis of Cations (Wilev-Interscience; Nature, 263, $802 ; 1976)$, the price was incorrectly quoted. This should read: $\$ 34.95 ; £ 20.85$.

- A UK edition of The Poverty of Power by Barry Commoner (for review, see Nature, 264, 134; 1976) has been published by Jonathan Cape, London, at £5.50. 